\title{
Effect of Evaporator Load on Heat Pump Operating Parameters and Performance
}

\author{
Mohammed Kamil and Saad Nazir \\ Mechanical \& Nuclear Engineering Department, University of Sharjah, PO Box 27272, Sharjah, UAE
}

\begin{abstract}
This work investigates the impact of varying the evaporator load on the performance and parameter characteristics of a heat pump. A series of experiments have been done on a vapor compression cycle heat pump which is run with R134a. The evaporator in this system is a coil submerged in a water/glycol bath accommodated in a thermally insulated steel container. The load of the evaporator is changed through a heater in this bath with a capacity of $1.8 \mathrm{~kW}$. The glycol bath is mixed through an electric stirrer. The results showed that system pressures and temperatures generally increase and then decrease after a certain heat load has been imposed. The same trend is for COP of the refrigeration system; hence there is an optimum load point to which the COP increases to a maximum and then starts to decline. This optimum point corresponds to the best efficiency of the system.
\end{abstract}

Key words: Heat pump, evaporator, COP, Refrigeration cycle.

\section{Introduction}

It is possible to say that any refrigeration system that works with the vapour compression cycle is a heat pump [1]. A heat pump is a device used to move the heat energy from low-temperature reservoirs to a high-temperature reservoir. It can be used for both heating and cooling [2]. The main components and processes in the heat pump are identical to any normal refrigeration cycle. If the heat pump is used for heating and cooling simultaneously, then a tremendous saving of energy can be attained since more heating effect can be obtained that the energy spent in the compressor [3]. In the heat pump, the refrigerant is circulated to the evaporator which is located outside. Initially, the refrigerant is in a low-pressure, low-temperature liquid state, but it soon absorbs enough heat from the outdoor air to raise its temperature to the boiling point. Upon reaching the boiling point, the refrigerant changes into a hot vapour or gas. This gas is then compressed by the compressor and circulated under higher pressure and temperature through the indoor coils, where it comes into contact

Corresponding author: Mohammed Kamil, Ph.D., assistant professor, research field: thermo-fluids. with the cooler room air that circulates around the coils. The cooler air causes the gas to cool, condense, and return to the liquid state. The condensation of the refrigerant vapour releases heat to the interior of the structure. After the refrigerant has returned to a liquid state, it passes through a particular pressure-reducing device (an expansion valve) and then back through the outdoor coils where the heating cycle begins all over again. The temperature of the room air that originally cooled the higher-temperature refrigerant vapour is itself increased by the process of heat transfer and recirculated throughout the room to provide the necessary heat [4].

Heat pumps are considered as a significant component in prospective buildings with low energy consumption [5]. A most effective way of improving the refrigeration cycle efficient is, of course, to improve the efficiency of its components [6]. Concerning air-to-air heat pump and refrigeration cycles, among possible options for optimisation, one advantageous measure is to search for an optimum refrigerant circuitry of the condenser and evaporator coils (trough appropriate junction of the coil tubes) $[7,8]$.

The objective of this study is to examine the impact of varying the load on the evaporator of a vapour 
compression refrigeration system with $\mathrm{R} 134 \mathrm{a}$ refrigerant on the heat pump performance parameters. The load is applied through an electric resistance heater inserted inside the glycol bath which surrounds the evaporator coil. The temperature of the glycol bath was varied by using a range of current values and its effect on functional parameters (system pressures and temperatures) was observed and analyzed. Increase of glycol bath temperature is termed as increased load.

\section{Methodology}

\subsection{Equipment Used}

The equipment used for the experiment is Cussons Refrigeration Unit employing vapour compression cycle operating as either a refrigerator or as a heat pump. Main components of the unit are as under.

\subsection{Compressor}

The compressor is a twin cylinder single stage unit (York type DA 206) with bore and strokes of $47.7 \mathrm{~mm}$ (1.875 in.) and $28 \mathrm{~mm}$ (1.105 in.) respectively giving a swept volume per revolution of $100 \mathrm{~cm}^{3}$ (6.11 in. ${ }^{3}$ ). The compressor is driven by a swinging field dynamometer motor via a toothed belt, the speed ratio is $1.33: 1$ reduction.

\subsection{Condenser}

The condenser is designed for contra-flow operation, (i.e. with the water flow in the opposite general direction to that of the refrigerant). This condenser has an overall length of $358 \mathrm{~mm}$ and effective heat exchange area of $0.47 \mathrm{~m}^{2}$.

\subsection{Expansion Valve}

The expansion valve is mounted behind the mimic panel, and the downstream line from the valve is fully heat insulated.

\subsection{Evaporator and Cold Reservoir}

The evaporator coil is submerged in a cold reservoir consisting of a thermally insulated stainless steel bath containing a water/glycol mixture as a heat transfer medium, and an electric immersion heater provides the refrigerating load. The current and hence the power input to the heater can be varied through a knob which is principally a variable resistor. This variation can be viewed as a load variation on the evaporator which is used as a baseline in this research. An electric stirrer mounted on the top cover of the cold reservoir unit assists circulation of the glycol mixture.

\subsection{Instrumentation}

2.6.1 Pressure Gauges (Mechanical Type)

- Compressor discharge pressure (0 to 16 barg)

- Compressor suction pressure (-1 to 3 barg)

- Expansion pressure (-1 to 3 barg)

2.6.2 Flow Gauges (Variable Area Type)

- Water flow rate 20-100 grams/sec (g/s)

- Refrigerant flow rate 1-13.5 grams/sec (g/s)

2.6.3 Temperature Measurement

Temperatures can be monitored at eight different locations in the apparatus using thermocouples and can be measured using the local display unit mounted on the equipment through a selector switch.

\section{Results and Discussion}

In this section, the results are presented for varying glycol bath temperature.

\subsection{Glycol Bath Temp vs. Discharge Pressure}

Fig. 1 shows the trends of the discharge pressure with the glycol bath temperature. There is an almost a linear rise in discharge pressure with the rise in load. However, this rise is sharper after the temperature $10{ }^{\circ} \mathrm{C}$ and onwards.

\subsection{Glycol Bath Temp vs. Suction Pressure}

Fig. 2 shows the variations of the suction pressure with the glycol bath temperature. There is almost linear rise in suction pressure with a rise in load, although it is a little less steep starting from $8{ }^{\circ} \mathrm{C}$ and onwards. 


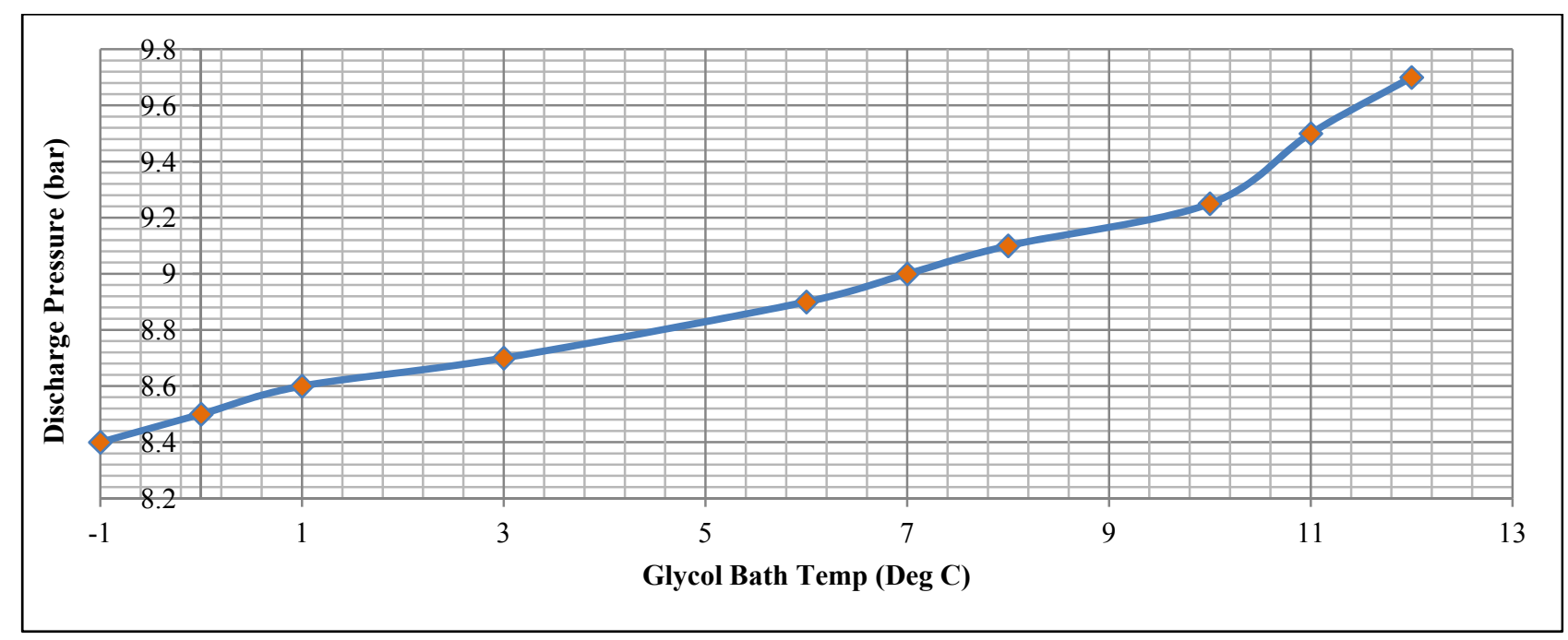

Fig. 1 Discharge pressure vs. glycol bath temperature.

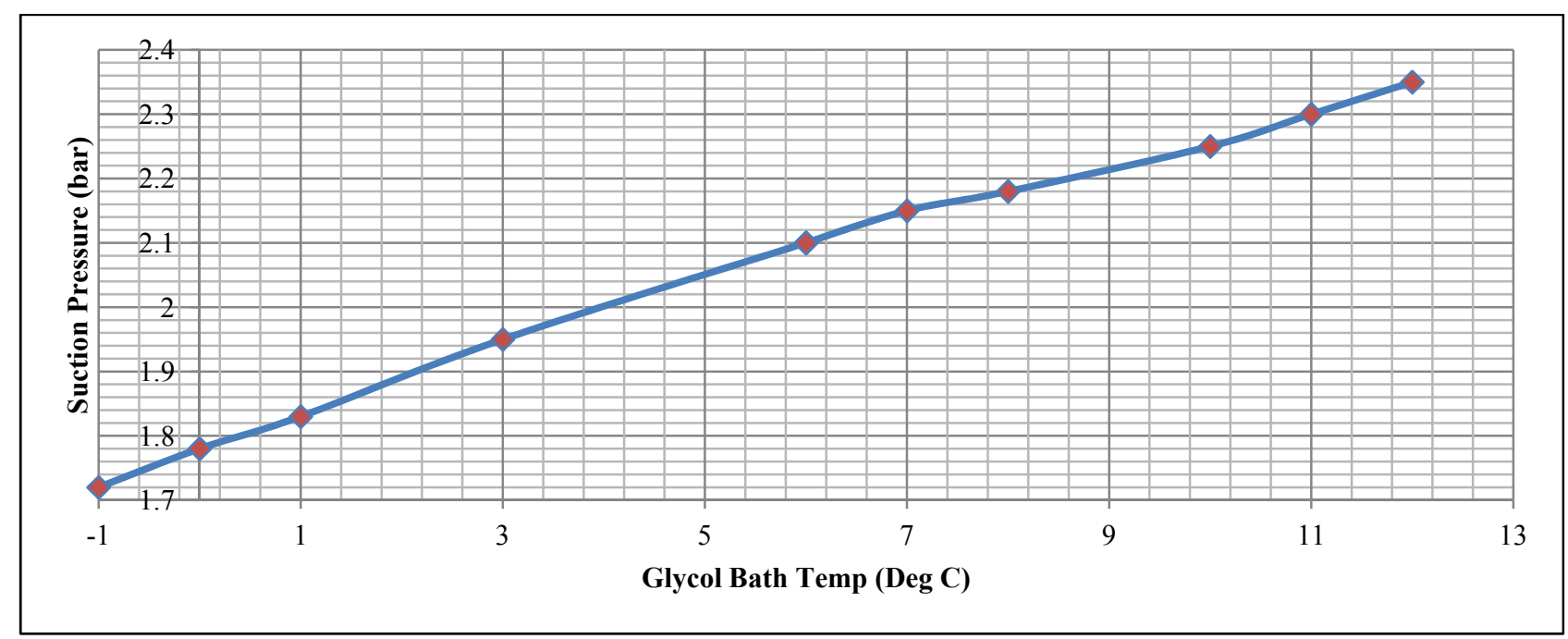

Fig. 2 Suction pressure vs. glycol bath temperature.

\subsection{Glycol Bath Temp vs. Expansion Pressure}

Fig. 3 shows the variations of the expansion pressure with the glycol bath temperature. Expansion pressure is slightly higher than evaporator pressure. This is pressure loss because of friction while flowing between the expansion valve and evaporator. Nevertheless, the graph has a similar pattern to suction pressure. Almost linear rise of pressure with the load but there is a small portion of the graph (between 6 and $7{ }^{\circ} \mathrm{C}$ ) where the pressure does not change with load.

\subsection{Glycol Bath Temp vs. Evaporator Inlet Temperature}

Fig. 4 shows the variations of the evaporator inlet temperature with the glycol bath temperature. Evaporator inlet temperature has a general increasing trend with a few exceptions. For very low load, $\left(-1\right.$ to $\left.0{ }^{\circ} \mathrm{C}\right)$ evaporator inlet temperature is dropping a little bit but then continues to rise until $9{ }^{\circ} \mathrm{C}$ glycol temperature. After that, it is showing a slightly decreasing trend after $10{ }^{\circ} \mathrm{C}$ glycol bath temperature.

\subsection{Glycol Bath Temp vs. Comp Outlet Temp}

Fig. 5 shows the variations of the compressor outlet temperature with the glycol bath temperature. Compressor outlet or discharge also follows a general increasing trend although there are fluctuations in the 


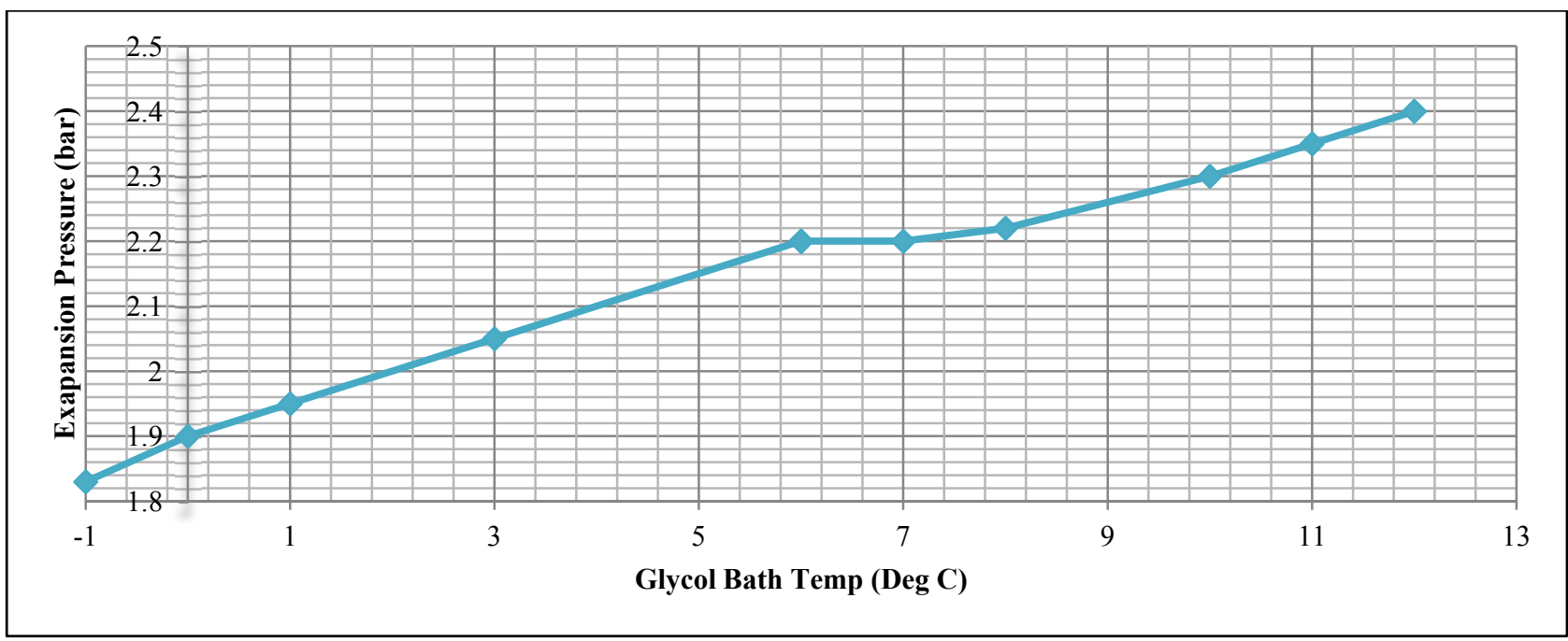

Fig. 3 Expansion pressure vs. glycol bath temperature.

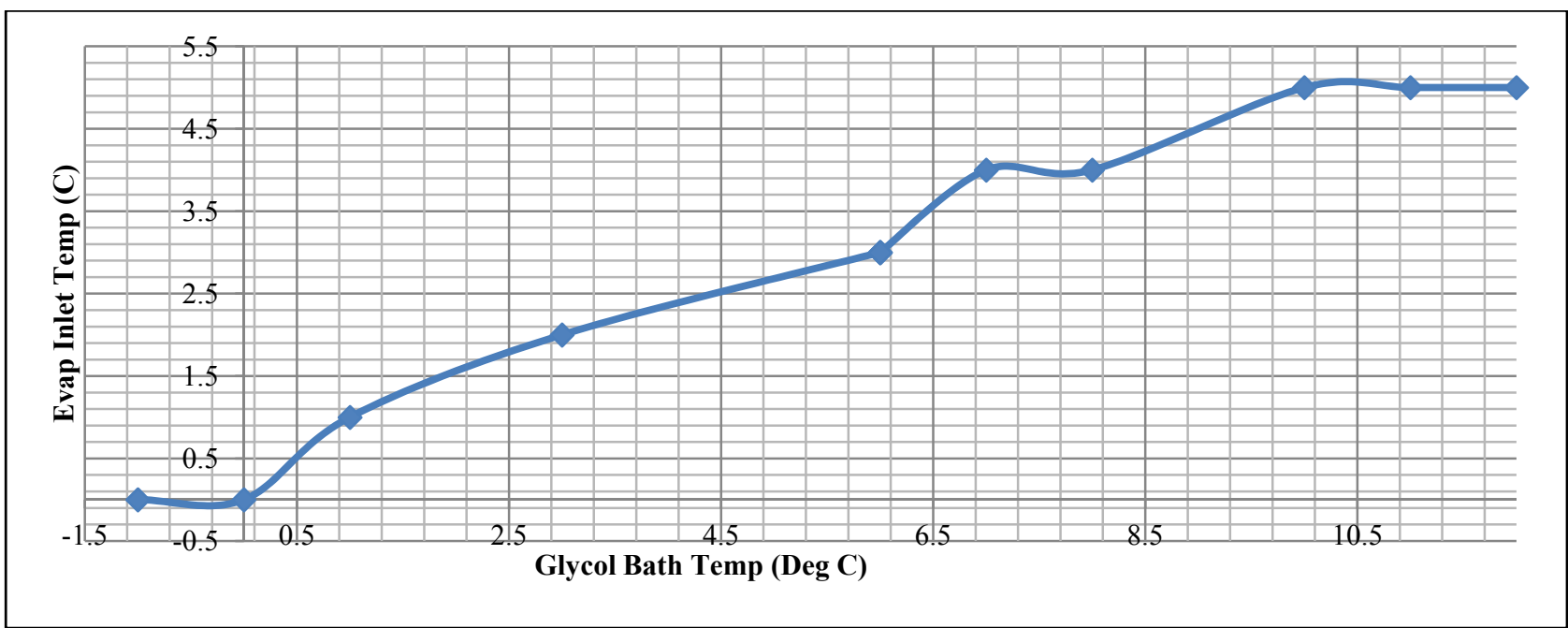

Fig. 4 Evaporator inlet temperature vs. glycol bath temperature.

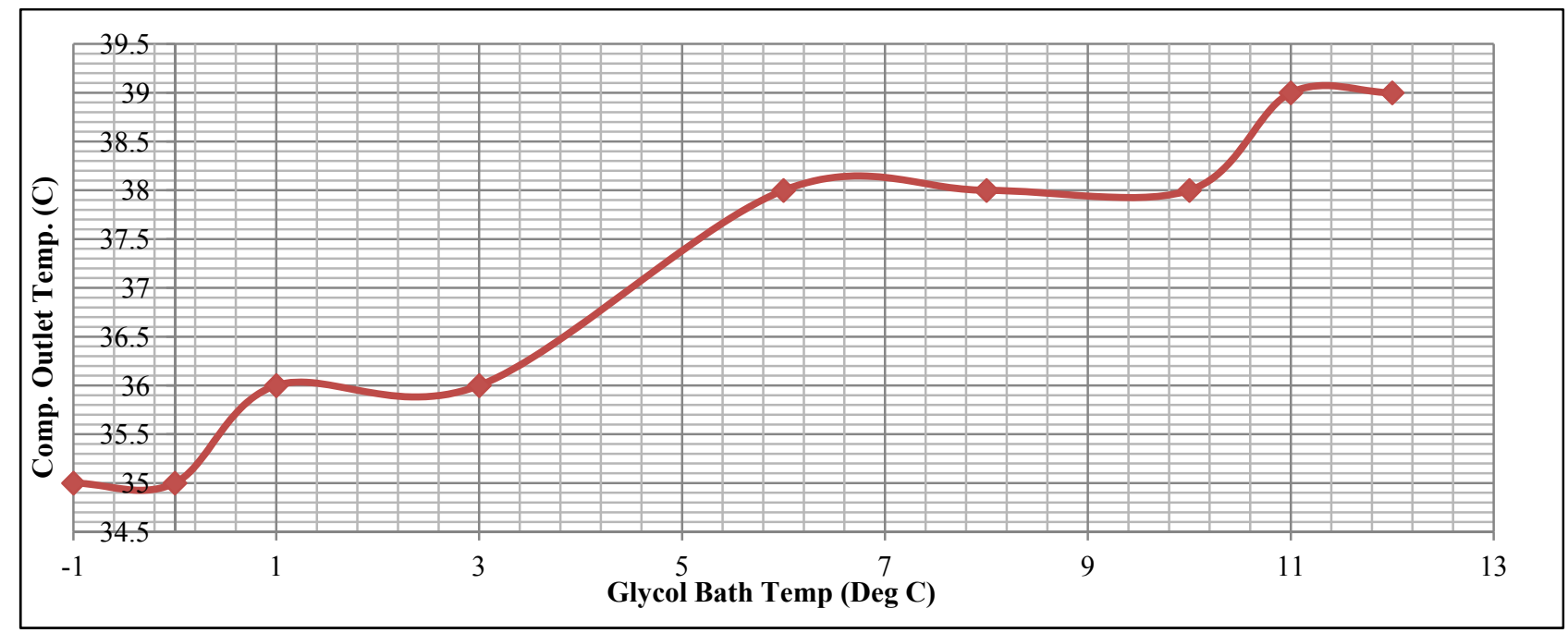

Fig. 5 Evaporator inlet temperature vs. glycol bath temperature. 


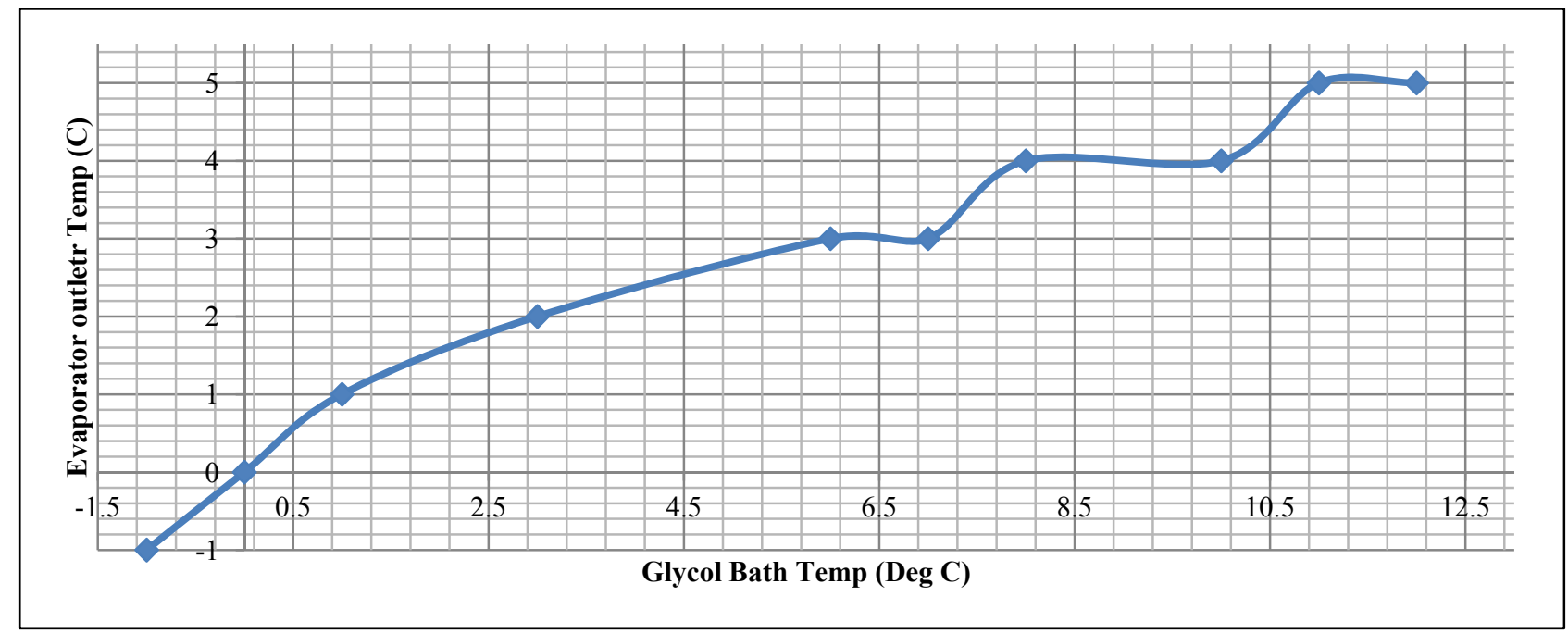

Fig. 6 Evaporator outlet temperature vs. glycol bath temperature.

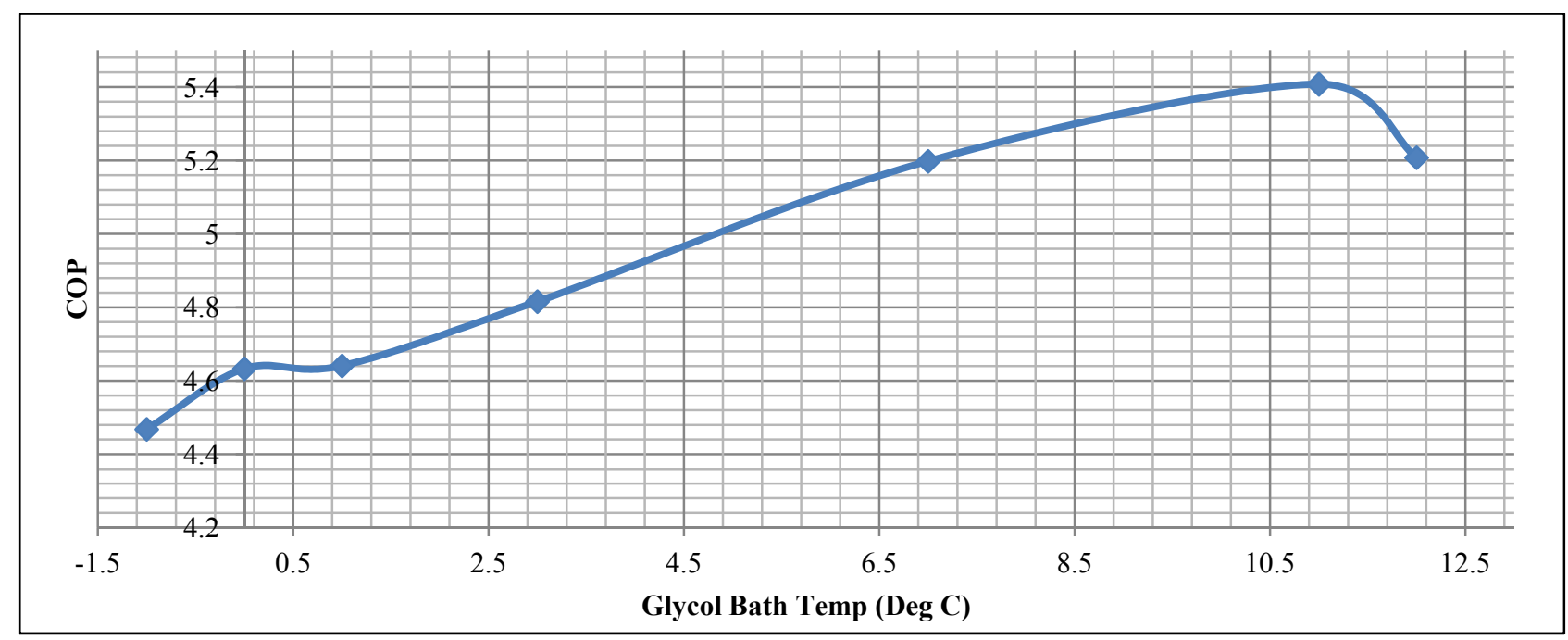

Fig. 7 Evaporator outlet temperature vs. glycol bath temperature.

pattern and a slight deviation at very low and at high temperatures. Starting from $-1{ }^{\circ} \mathrm{C}$ till $0{ }^{\circ} \mathrm{C}$ the compressor outlet temperature is showing a decreasing trend possibly due to very cold refrigerant entering the suction side of the compressor. Later there is an increasing trend until $7{ }^{\circ} \mathrm{C}$ then a slight fluctuation shows a slightly decreasing trend onwards till the glycol temperature is $10{ }^{\circ} \mathrm{C}$. There is a steep rise for next temperature change and again a slight downfall.

\subsection{Glycol Bath Temp vs. Evaporator Outlet Temp}

Fig. 6 shows the variations of the evaporator outlet temperature with the glycol bath temperature. Evaporator outlet or discharge also follows a general increasing trend although there are slight fluctuations in the pattern and an apparent slight deviation at high temperature. There is an increasing trend until 6 degrees then a slight fluctuation shows a slightly decreasing trend onwards till the glycol temperature is $8{ }^{\circ} \mathrm{C}$. There is a steep rise for next temperature change and again a slight downfall.

\subsection{Evaporation Temperature vs. COP}

Fig. 7 shows the variations of the evaporator outlet temperature with the glycol bath temperature. Coefficient of performance (COP), which is an indicator of the overall performance of the refrigeration system exhibits a general increasing 
trend although non-linear throughout. Again, at a higher temperature of glycol bath, there is a drop in COP which is quite sharp.

\section{Conclusion}

It can be concluded from the results obtained that with increasing load on the evaporator, the system pressures and temperatures generally increase and then decrease after a specific heat load has been imposed. The same trend is for COP of the refrigeration system; hence there is an optimum load point to which the COP increases to a maximum and then starts to decline. This optimum point corresponds to the best efficiency of the system.

\section{References}

[1] McQuiston, F. C., Parker, J. D., and Spitler, J. D. 2005. Heating, Ventilating, and Air Conditioning; Analysis and Design, 6th ed. New York: John Whiley \& Sons, Inc.

[2] Mitchell, J. W., and Braun, J. E. 2013. Principles of
Heating, Ventilation, and Air Conditioning in Buildings. New York: John Whiley \& Sons, Inc.

[3] Brumbaugh, J. E. 2004. HVAC Fundamentals: Air Conditioning, Heat Pumps and Distribution Systems, 4th ed. New York: Whiley Publishing, Inc.

[4] ASHRAE. 2018. American Society of Heating, Ventilation, Refrigeration, and Air Conditioning Engineers. Refrigeration Handbook. Atlanta USA.

[5] IEA Heat Pump Centre. 2012. "The Role of Heat Pumps in Net Zero Energy Buildings." IEA Heat Pump Centre Newsletter 30 (3): 3.

[6] Martínez, L. C. C., Parise, J. A. R., Motta, S. F. Y., and Becerra, E. C. V. 2010. "Plate Fin and Tube Heat Exchangers Refrigerant Circuiting Optimization in Vapor Compression Refrigeration Systems." International Refrigeration and Air Conditioning Conference.

[7] Fowler, A. J., Ledezma, G. A., and Bejan, A. 1997. "Optimal Geometric Arrangement of Staggered Plates in Forced Convection." International Journal Heat Mass Transfer 40 (8): 1795-805.

[8] Matos, R. S., Vargas, J. V. C., Laursen, T. A., and Bejan, A. 2004. "Optimally Staggered Finned Circular and Elliptic Tubes in Forced Convection." International Journal of Heat and Mass Transfer 47: 1347-59. 